\title{
Circadian Characteristics of Special Glazing
}

\author{
By Peter Hartman* \\ Paulina Sujanova ${ }^{\dagger}$ \\ Jozef Hraska
}

The window provides the natural daylight for the indoor environment. Recent discoveries in photobiology found, that light, especially natural daylight not only enables visual performance but has even more effects on the human body. Light properties in a longterm inhabited environment can seriously influence the health state and well-being of occupants. The non-visual effects on the human body are linked to the maintenance of our circadian rhythms, including sleep cycles, metabolism, core temperature and a large number of biological processes in our body. Sick Building Syndrome $(S B S)$ is also a frequented issue. Inappropriate lighting in the indoor environment is assumed to be one of the reasons of sick building syndrome occurrence which is connected to Seasonal Affective Disorders (SAD). The parameters of indoor light climate can be influenced by the selection of window glazing. The presented paper deals with a two way evaluation of spectral characteristics of a selection of special window panes. The scale of samples includes various tinted glasses, low emissivity window panes and other modern window glazing. In the first part, spectral transmittance of the samples is measured with a spectrophotometer. The outputs are classified in terms of their visual and photobiological response. The second part includes measurements, where some of the selected samples are used in our experimental models. One of the models is considered to be the reference model equipped with single clear glass. The internal surfaces of all models are in spectrally neutral colours. All other models have a window equipped with a sample of chosen special glazing. The light conditions used for these longerterm observations are covered by natural daylight. The measuring devices are located in the models so that the visual response and also non-visual impact of light parameters inside the models can be recorded. The experiment demonstrates, that despite very high external illuminance, selected tinted glazing causes filtration of almost one half of the SPD doses in comparison with the reference model with clear glass. The measurements were made in four positions related to the window. This reflected worse results for

${ }^{*} \mathrm{PhD}$ Student, Slovak University of Technology, STU, Slovakia.

${ }^{\dagger} \mathrm{PhD}$ Student, Slovak University of Technology, STU, Slovakia.

"Professor, Slovak University of Technology, STU, Slovakia. 
monitored parameters devoted to non-visual response - the normalized circadian light CLA and circadian stimulus CS. The measurements were repeated with included external shading obstacles which simulated an adjacent building. The differences were more noticeable for all positions.

\section{Introduction}

The circadian photometry is gaining more focus in many fields of science including building structures. The ambient light that penetrates in our eyes has an influence on our mood, attention, performance and is also responsible for the synchronization of the biological clock located in the suprachiasmatic nuclei $(\mathrm{SCN})$ in our brain [1-2]. The discovery of the new photoreceptor in the human eye opened a new frame of reference on indoor light conditions evaluation [3]. The photoreceptor is known as intrinsically photosensitive retinal ganglion cells (ipRGC) [4]. The circadian response on light conditions is complex and depends on exposure timing, duration, intensity and spectral power distribution (SPD) of the light source [5]. Circadian rhythms exist, with different characteristics, in animals as well as in plants. These rhythms are the result of adaptation of live organisms to the light/dark pattern [6]. Without exposure to a regular 24-hour day-night rhythm, there is a risk of circadian disruption consequences that are connected to various health problems [7-9] Previous experiments proved that suitable maintenance of circadian rhythms demands higher requirements on indoor light conditions than just visual response [10]. These proceedings were applied for the evaluation of non-visual impact of light. Firstly the experiment is done without shading and then the experiment is repeated with included external dark coloured shading with equivalent shading angle of $30^{\circ}$.

\section{Computational Model for Circadian Response}

\section{The Method for Circadian Response Evaluation According to Rea}

Rea suggests a model for phototransduction based on previous experimental measurements executed by Brainard [11] and Thapan [12]. Both scientists made measurements on the impact of light on nocturnal melatonin suppression caused by monochromatic light sources. Previous experiments mentioned, that not only ipRGC controls the circadian response, but also other photoreceptors - the rods and cones [13]. Latest researches stated that data from Brainard and Thapan acquired with monochromatic light sources may be inappropriate, because the effect of $b-z$ opposite channel is not included [14]. Brainard and Thapan`s data at around $500 \mathrm{~nm}$ are irregular, and the fitting curve shows a discontinuity point. Rea's research mentioned that this can be explained by the fact that ipRGC covers wavelengths longer than $500 \mathrm{~nm}$ for circadian response with the peak sensitivity at $480 \mathrm{~nm}$. Circadian response for 
wavelengths shorter than $500 \mathrm{~nm}$ depends on the combined effect of ipRGC and S-cones (peaks at $440 \mathrm{~nm}$ ), with the further attenuating contribution of the rod-response [15]. This effect can cause serious differences in results from polychromatic light stimuli and the corresponding sum of monochromatic light stimuli. Rea defined a new specific unit - circadian light $C L_{A}\left[\mathrm{~W} / \mathrm{m}^{2}\right](1-4)$, which represents radiation in visible range with no optical impact on human response, but causes biological stimulus [15]. The mathematical equations defined for Rea`s model in Fig. 1 include b-y opposite channel, and spectral sensitivity of both visual and non-visual photoreceptors.

Figure 1. Nocturnal Melatonin Suppression Data from Brainard [11] and Thapan [12] for Narrowband Spectrum and Illustration of Spectral Sensitivity Function resulting from Exposure to Narrowband Light (Solid Curve). Second (Dashed Line) Expresses Broadband Polychromatic Illumination with Exhibition of Spectral Opponency [14]

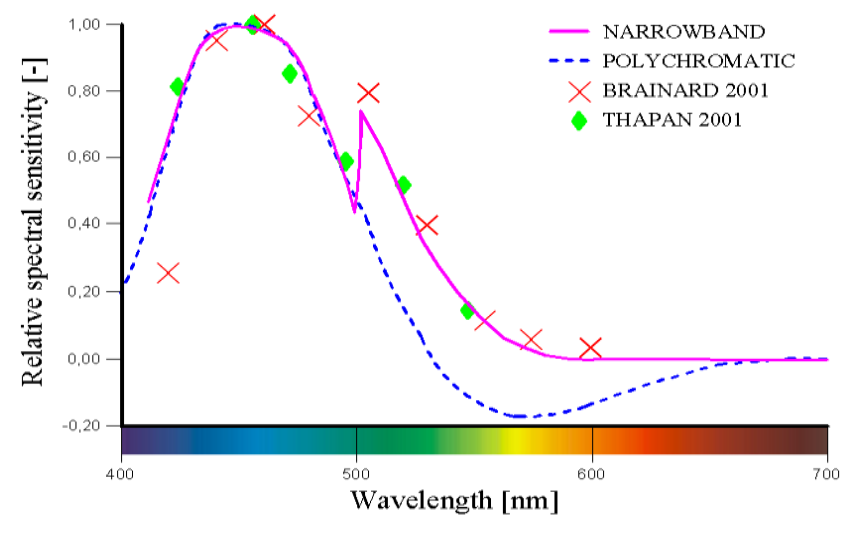

$$
C L_{A}=1622 \int M_{C_{\lambda}} E_{\lambda} d \lambda\left(a_{b-y}\left(\left.\int \frac{s_{\lambda}}{m p_{\lambda}}\right|_{n r m} E_{\lambda} d \lambda\right)-a_{r o d}\left(1-e^{-\left(\frac{\int V_{\lambda}^{\prime} E_{\lambda} d \lambda}{\text { RodSat }}\right)}\right)\right)
$$

if

$\int \frac{s_{\lambda}}{m p_{\lambda}} E_{\lambda} d \lambda-k \int \frac{V_{\lambda}}{m p_{\lambda}} E_{\lambda} d \lambda \geq 0$

or

$$
C L_{A}=1622 \int M_{C_{\lambda}} E_{\lambda} d \lambda \quad \text { if } \quad \int \frac{s_{\lambda}}{m p_{\lambda}} E_{\lambda} d \lambda-k \int \frac{V_{\lambda}}{m p_{\lambda}} E_{\lambda} d \lambda \leq 0
$$

where

$C L_{A} \quad$ Normalized circadian light. The constant, 1622, sets the normalization of $C L_{A}$ so that $2856 \mathrm{~K}$ blackbody radiation at 1000 lux has a $C L_{A}$ value of 1000 [15],

$E_{\lambda}$ represents light source spectral irradiance $\left[\left(\mathrm{W} / \mathrm{m}^{2}\right) / \mathrm{nm}\right]$,

$V_{\lambda} \quad$ is the Photopic luminous efficiency function,

$V_{\lambda}^{\prime} \quad$ is the rod spectral efficiency function, 
$M_{\lambda} \quad$ is the melanopsin-containing retinal ganglion cell spectral efficiency function (corrected for crystaline lens transmittance) function [15],

$s_{\lambda} \quad$ spectral sensitivity of S-cones [16],

RodSathalf-saturation constant for bleaching rods $=6.5 \mathrm{~W} / \mathrm{m}^{2}$,

$\Delta \lambda \quad$ wavelength increment from $380 \mathrm{~nm}$ to $580 \mathrm{~nm}(780 \mathrm{~nm})$.

$k \quad 0.2616 ; a_{b-y}=0.6201 ; a_{\text {rod }}=3.2347$ [15].

\section{The Method for Circadian Response Evaluation According to Bellia}

Bellia starts from Rea`s model, but tries to make the calculation simpler. The circadian action factor $a_{c v}$ [17] was used for $C L_{A}$ computation.

Bellia`s method declares an excellent match for light sources with correlated color temperature $(C C T)$ from $2500 \mathrm{~K}$ to $6500 \mathrm{~K}$ and blackbody radiator (color temperature $C T$ from $1000 \mathrm{~K}$ to $10000 \mathrm{~K}$ ) with Rea`s model [14]. This modification may be very important for consequent research in nonvisual light impact on humans. Both computational methods continue with the same definition of melatonin suppression efficacy - the circadian stimulus $C S$ [-]. This unit reflects how effective the light source is, on the suppression of melatonin concentration level in the body after one hour exposure.

$$
C S=0.75-\frac{0.75}{1+\left(\frac{C L_{A}}{215.75}\right)^{0.864}} \quad[-]
$$

\section{Description of the Experiment}

\section{Models}

This paper deals with an experiment devoted to the demonstration of the influence of special glazing on indoor daylight climate according to Rea s method evaluation. There are four same sized office room models in the scale of 1:5 (model dimensions are $600 \times 600 \times 2000 \mathrm{~mm}$ ) in Fig. $2-3$ exposed to natural daylight conditions on the flat roof of the Faculty of Civil Engineering, STU in Bratislava, Slovakia. All the internal surfaces of models are white. The models have an opening $400 \times 300 \mathrm{~mm}$ equipped with single glazing. Three models are tested with selected special glazing and one is a reference model with clear glazing. Spectral transmittance of the glazing samples is shown in Fig. 5. 
Figure 2. Experimental Model Scheme and Photo - Longitudinal Section (Left) and Photo of Models (Right)
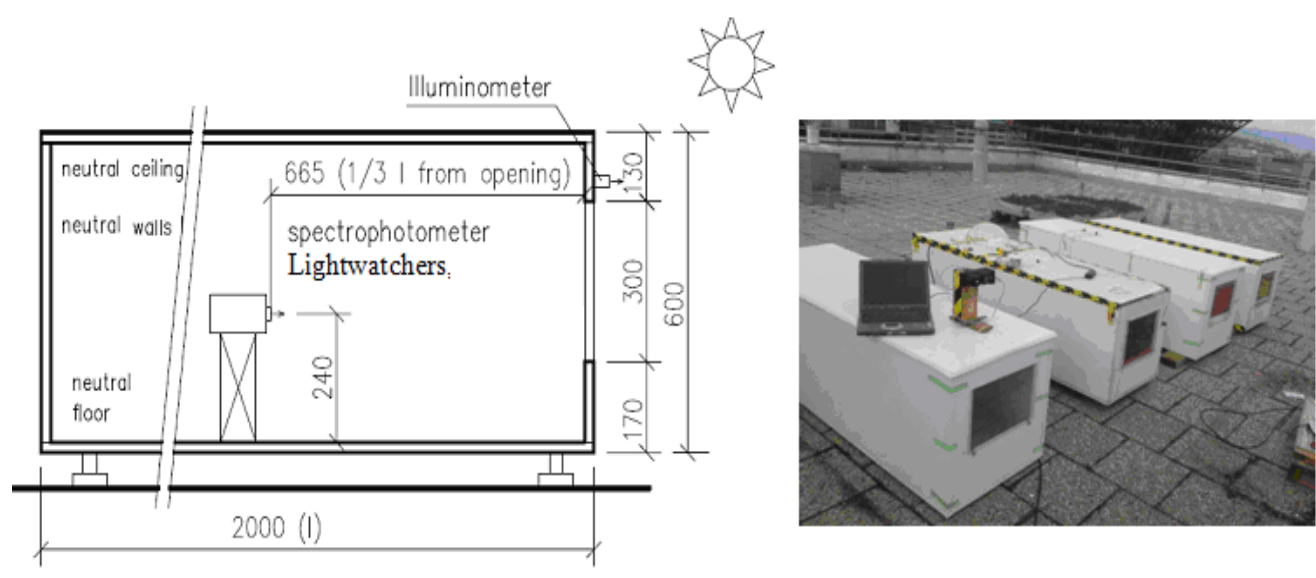

Figure 3. Experimental Model - Position of the Device and Illustration of the External Shading Obstacle

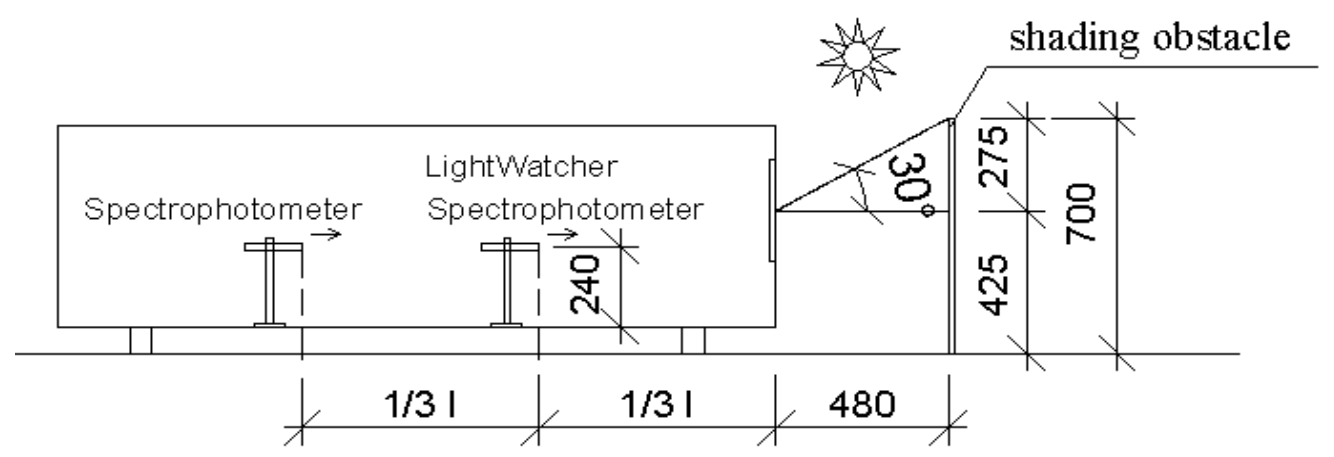

Window openings are oriented to the south-east. The absolute transmittance values are shown in Fig. 4. The following tinted glazing types were used:

1; Planibel Bronze $4 \mathrm{~mm}$

2; Planibel Green $4 \mathrm{~mm}$

3; Antelio Blue $6 \mathrm{~mm}$

4; Clear glass $4 \mathrm{~mm}$

During the investigation, internal SPD levels were measured in four ways. The spectrophotometer was directed to the window opening and opposite internal wall in $1 / 3$ and $2 / 3$ of models length in Table 2-3. At first, the measurement was done without shading. Immediately after that, the measurement was repeated with the use of dark coloured external shading obstacle in Fig. 3 with spectral reflectance value defined in Fig. 4.

Devices

Spectrophotometer Konica Minolta CM-5 was used for the measurement of spectral transmittance of the selected glazing and spectral reflectance of internal surfaces and external shading obstacle. Sensitivity of the device is 10 
$\mathrm{nm}$ with range from 360 to $740 \mathrm{~nm}$. The device was used for the investigation of spectral transmittance of glazing and spectral reflectance of surfaces. After that, absolute transmittance and reflectance values were defined according to luminous efficiency function $V_{\lambda}$ and circadian response curve $C_{\lambda}$ according to Gall [18].

The LightWatcher - light dosimeter which operates in 5 light bands - UV, blue, green, red, IR, sampling every $30 \mathrm{~s}$ [19]. The device also calculates the photopic illuminance levels. The LightWatchers were used for recording internal daylight illuminance levels and illustration of light colour.

The Konica Minolta CL-500A was used for the investigation of modified indoor daylight SPD levels in all defined positions. The outputs of SPD were used as the primary input for our calculation program based on Rea`s computational model method. The device also enables measurement of CIE chromacity coordinates, so there is a possibility to compare both of the computational methods in future. The measurements were done in June, close to midday. Exterior optimal light conditions and the use of single glazing abate negative impact of inappropriate glazing on indoor daylight climate. Despite this, an influence was declared under clear sky conditions with very high external illuminance.

\section{The Outputs from the Experiment}

The results are divided in two groups. First, the outputs acquired from investigation of tinted glazing influence on indoor daylight parameters without external shading obstacle (Fig 4-11) are presented. Subsequently, the results with the inclusion of external shading with dark surface in Fig 12-17 are shown.

The Outputs of the Experiment without Shading Obstacle

Figure 4. Absolute Transmittance of Selected Tinted Glazing and Absolute Reflectance of Surfaces used for the Experiment

\begin{tabular}{|c|c|c|c|c|c|}
\hline \multirow{3}{*}{$\begin{array}{l}\text { Sample of tinted } \\
\text { glazing }\end{array}$} & \multicolumn{2}{|c|}{$\begin{array}{c}\text { Absolute } \\
\text { transmittance level }\end{array}$} & \multirow{3}{*}{$\begin{array}{c}\text { Sample of } \\
\text { surface }\end{array}$} & \multicolumn{2}{|c|}{$\begin{array}{c}\text { Absolute } \\
\text { reflectance level }\end{array}$} \\
\hline & Photopic & Circadian & & Photopic & Circadian \\
\hline & $\tau_{V}[-]$ & $\tau_{C}[-]$ & & $\tau_{V}[-]$ & $\tau_{C}[-]$ \\
\hline Planibel Bronze $4 \mathrm{~mm}$ & 0.62 & 0.57 & \multirow{2}{*}{$\begin{array}{l}\text { Internal } \\
\text { white }\end{array}$} & \multirow{2}{*}{0.87} & \multirow{2}{*}{0.94} \\
\hline Planibel Green 4 mm & 0.79 & 0.79 & & & \\
\hline \begin{tabular}{|l} 
Antelio Blue $6 \mathrm{~mm}$ \\
\end{tabular} & 0.57 & 0.69 & External & \multirow{2}{*}{0.13} & \multirow{2}{*}{0.07} \\
\hline Clear glass $4 \mathrm{~mm}$ & 0.90 & 0.90 & shading & & \\
\hline
\end{tabular}

The experiment without shading obstacle proved that despite the noticeable lower absolute transmittance levels of selected tinted glazing, the final monitored unit, the $C S$, gives suitable values. In Fig. 8, the impact of glazing on visible spectrum dose is clearly visible. 
Figure 5. Spectral Transmittance of Selected Tinted Glazing (5a) and Spectral Reflectance of Internal Surfaces and External Shading Obstacle used in Experiment $(5 b)$

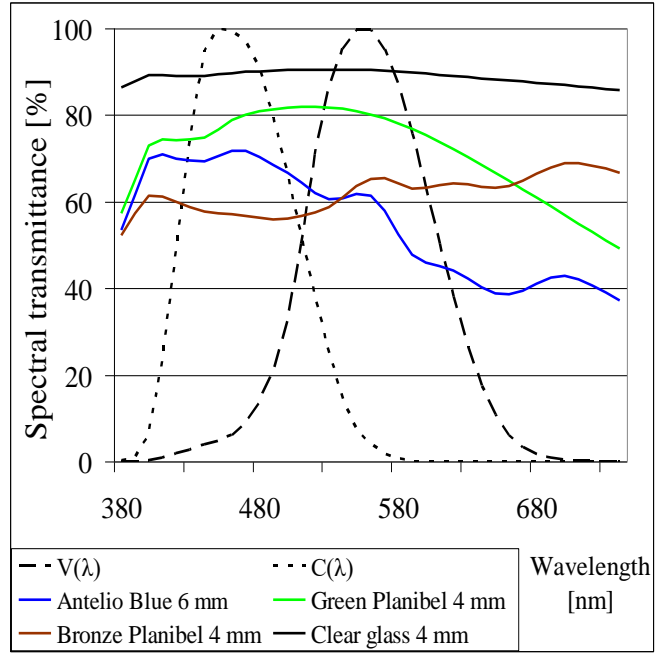

$5 \mathbf{a}$

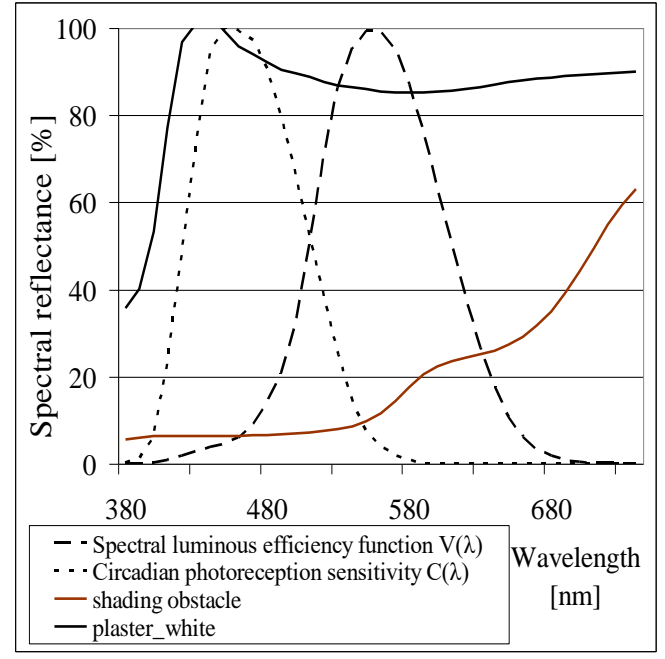

$5 \mathbf{b}$

From Figures 4-5, it is clear that selected tinted glazing have noticeable different spectral characteristics. Planibel Bronze has absolute photopic and circadian transmittance much lower than clear glass.

Figure 6. SPD Levels Recorded in 1/3 (6a) and 2/3 (6b) of the Model Rooms Length Oriented to Window

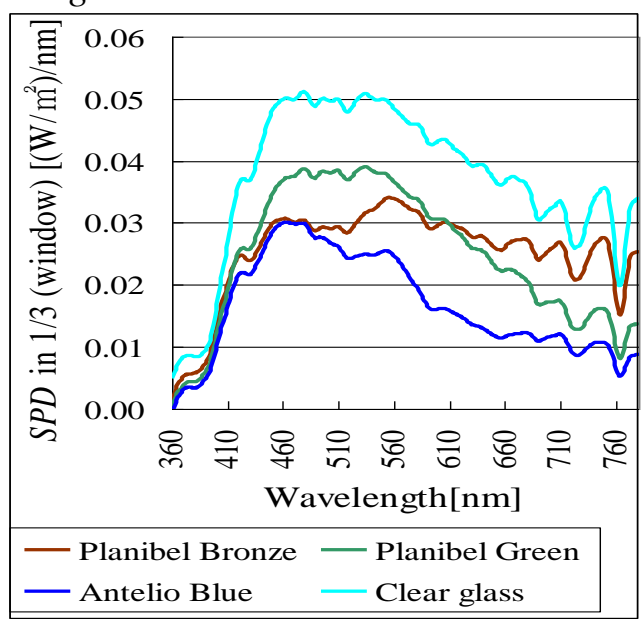

$6 \mathbf{a}$

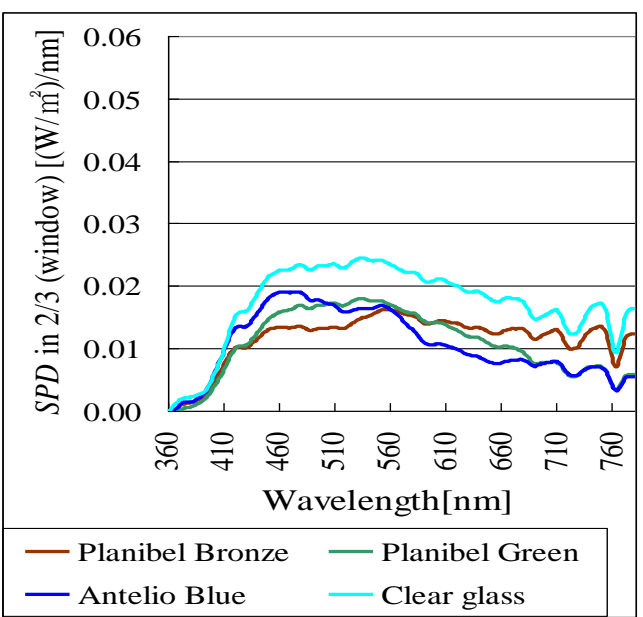

$6 \mathbf{b}$ 
Figure 7. SPD Levels Recorded in $1 / 3$ (7a) and 2/3 (7b) of Model Rooms Length Oriented to Wall

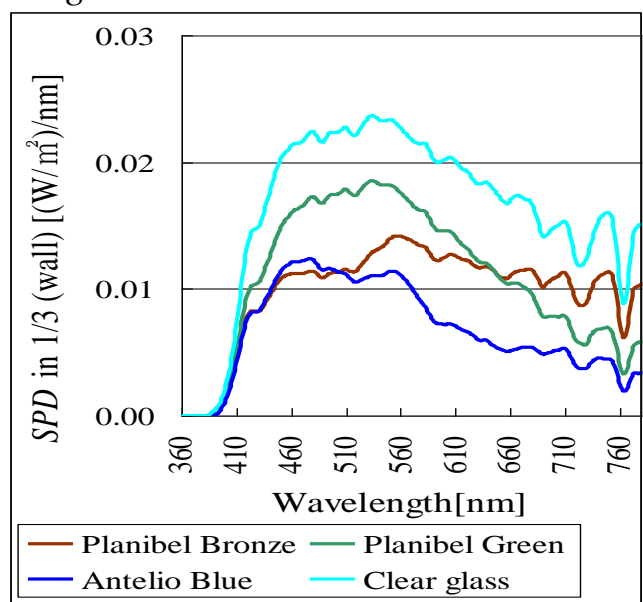

$7 \mathbf{a}$

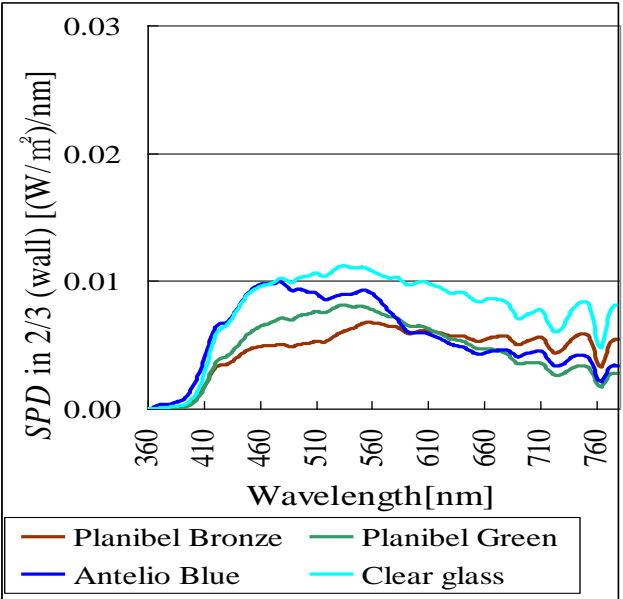

$7 \mathbf{b}$

Figure 8. Results of SPD Levels Recorded in All Positions in All of the Models. The Ratios of SPD Levels Measured in Tested Models Compared to SPD Values in Reference Model for Two Spectral Ranges are Defined.

\begin{tabular}{|c|c|c|c|c|c|c|c|c|}
\hline \multirow{3}{*}{$\begin{array}{l}\bar{\Phi} \\
\bar{O} \\
\Xi \\
\mathbb{E} \\
\mathbb{E}\end{array}$} & \multicolumn{8}{|c|}{ Absolute dose of visible spectrum $\left[\left(\mathrm{W} / \mathrm{m}^{2}\right) / \mathrm{nm}\right]$} \\
\hline & \multicolumn{4}{|c|}{ Wavelength interval 380-580nm } & \multicolumn{4}{|c|}{ Wavelength interval 380-780nm } \\
\hline & $\begin{array}{c}1 / 3 \\
\text { window }\end{array}$ & $\begin{array}{c}1 / 3 \\
\text { wall }\end{array}$ & $\begin{array}{c}2 / 3 \\
\text { window }\end{array}$ & $\begin{array}{c}2 / 3 \\
\text { wall }\end{array}$ & $\begin{array}{c}1 / 3 \\
\text { window }\end{array}$ & $\begin{array}{c}1 / 3 \\
\text { wall }\end{array}$ & $\begin{array}{c}2 / 3 \\
\text { window }\end{array}$ & $\begin{array}{c}2 / 3 \\
\text { wall }\end{array}$ \\
\hline Bronze & 5.47 & 1.97 & 2.39 & 0.89 & 10.69 & 4.16 & 4.90 & 1.97 \\
\hline Green & 6.32 & 2.72 & 2.71 & 1.13 & 10.46 & 4.62 & 4.58 & 2.00 \\
\hline Blue & 4.63 & 1.83 & 2.92 & 1.51 & 7.02 & 2.87 & 4.49 & 2.40 \\
\hline Reference & 8.56 & 3.57 & 3.84 & 1.64 & 15.63 & 6.83 & 7.25 & 3.27 \\
\hline \multicolumn{5}{|c|}{$\begin{array}{l}\text { The proportion of SPD in tested models compared } \\
\text { to reference model }\end{array}$} & \multicolumn{4}{|c|}{$\begin{array}{l}\text { The proportion of SPD in tested } \\
\text { models compared to reference model }\end{array}$} \\
\hline Bronze & 0.64 & 0.55 & 0.62 & 0.54 & 0.68 & 0.61 & 0.68 & 0.60 \\
\hline Green & 0.74 & 0.76 & 0.71 & 0.69 & 0.67 & 0.68 & 0.63 & 0.61 \\
\hline Blue & 0.54 & 0.51 & 0.76 & 0.92 & 0.45 & 0.42 & 0.62 & 0.73 \\
\hline Reference & 1.00 & 1.00 & 1.00 & 1.00 & 1.00 & 1.00 & 1.00 & 1.00 \\
\hline
\end{tabular}

Figure 9. Photopic Illuminance Levels Recorded in All Positions in All Models

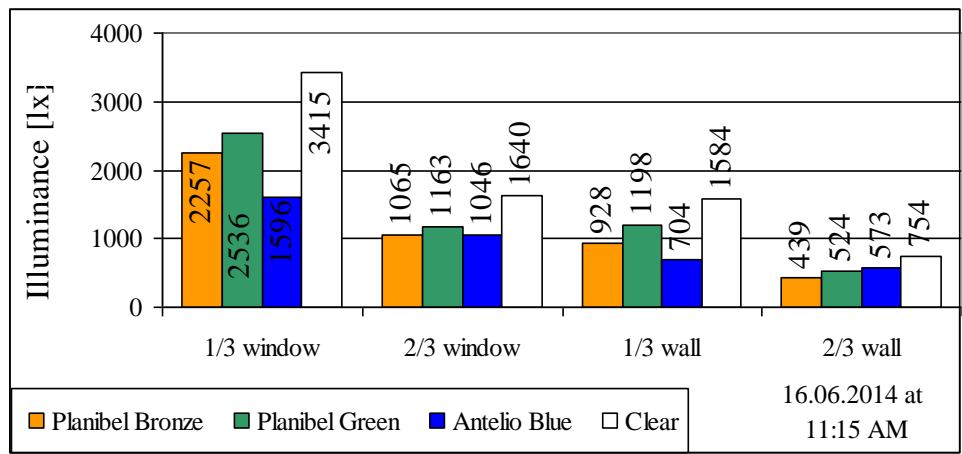


In some positions, there is only one half of SPD dose in comparison with clear glass. A similar effect can be seen in illuminance level in Fig. 9. An evident decrease of illuminance level and $C L_{A}$ (in Fig. 10) can be seen when moving further from the window.

Figure 10. $C L_{A}$ Levels Estimated with Rea's Equation for All Positions in All of the Models

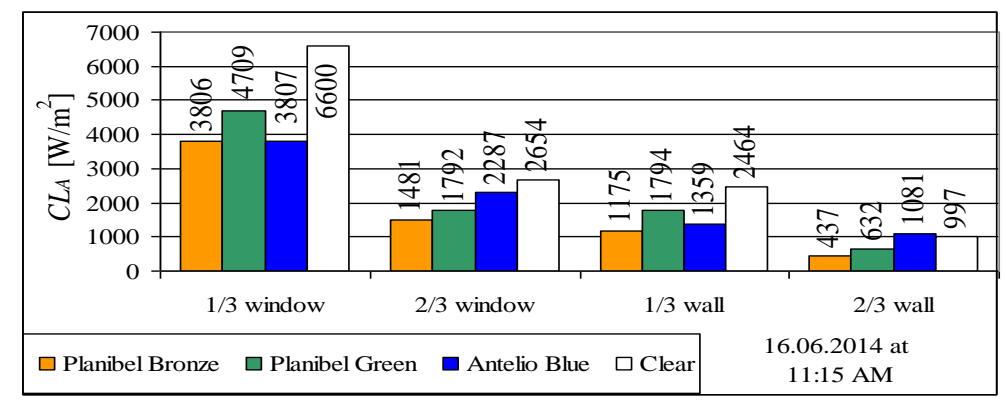

Figure 11. Computed CS Levels Acquired from Rea's Model in All Positions in All of the Models - without External Obstruction

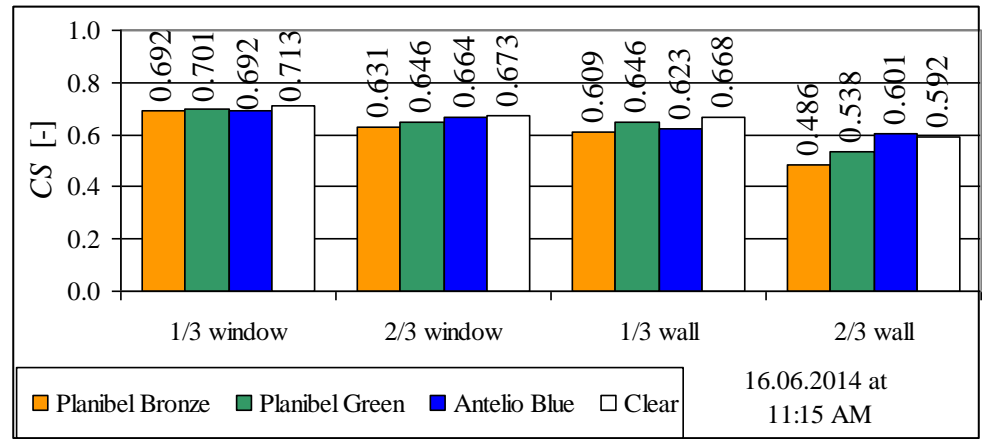

During midday in June with clear sky, the external light conditions were more than suitable for covering both a visual and non-visual response. The results from Fig. 11 prove that. The $C S$ levels are close to max value -0.75 except for the last position, where with especially bronze tinted glazing, the results have worsened. It is questionable how this can influence the use of external shading with dark colour.

\section{The Outputs of the Experiment with Shading Obstacle}

As illustrated in Fig. 3, the shading obstacle causes 30 degrees of shading angle. Noticeable illuminance level decrease is expected, but as stated before, higher illuminance level for non-visual effect is needed unlike for visual response. Fig. 14 illustrates that the obstacle prevents a substantial part of directly penetrated daylight to enter, and higher differences are revealed. It must be noted, that the external light conditions were in principle the same. 
Figure 12. SPD Levels Recorded in 1/3 (12a) and 2/3 (12b) of Model Room 's Length Oriented to Window

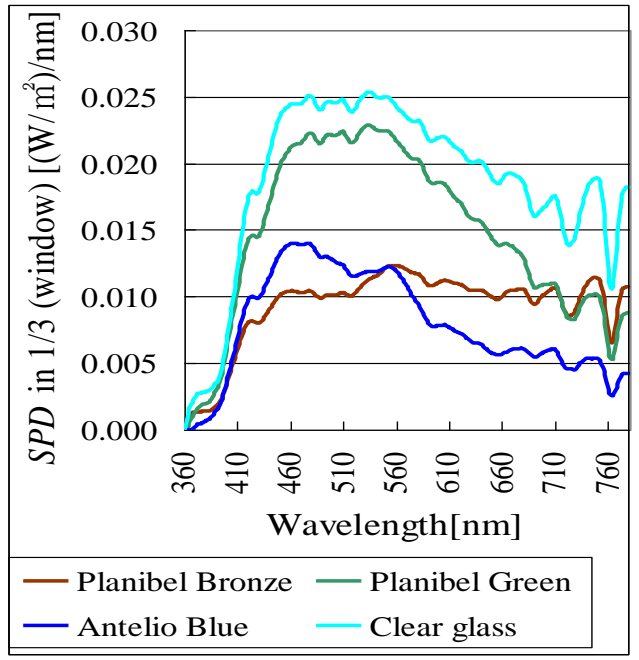

12a

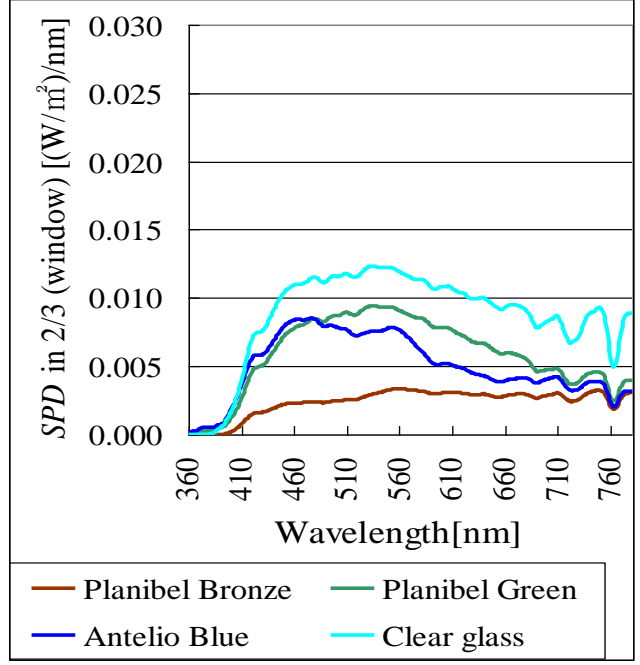

$12 b$

Figure 13. SPD Levels Recorded in 1/3 (13a) and 2/3 (13b) of Model Room 's Length Oriented to Window

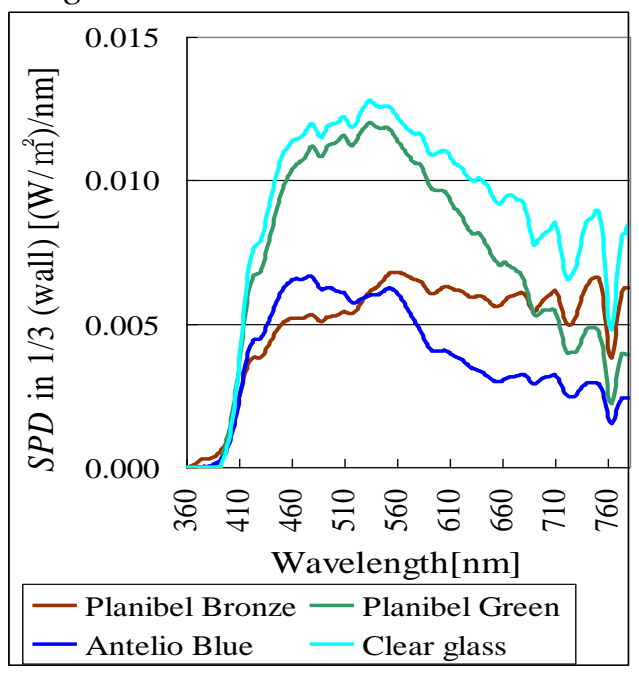

13a

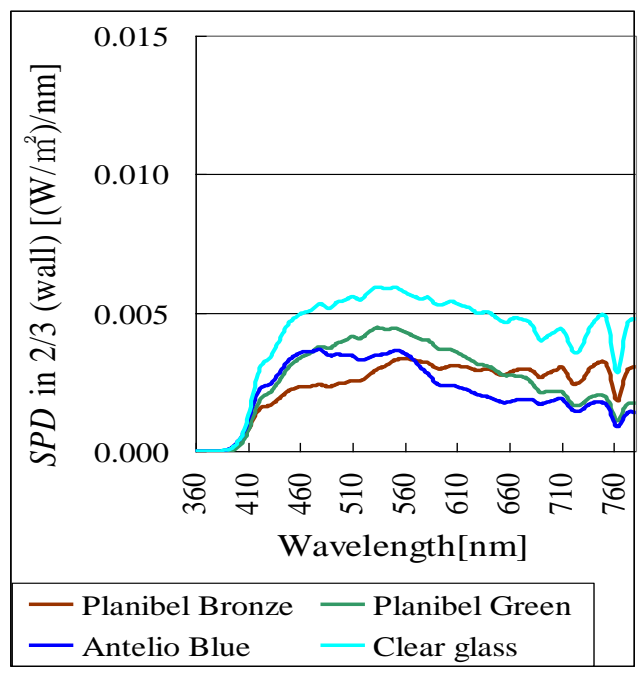

$13 b$

The shading obstacle caused a decrease of about $50 \%$ in the SPD levels (in Fig. 12-13). It was expected, that lower daylight dose evokes substantial worsening of $C L_{A}$ and $C S$ values. In the first case, without obstacle, the height illuminance level decreased significantly the negative effect of glazing. The inclusion of obstacle demonstrates more real conditions for the city. Fig. 14 illustrates expected negative changes in comparison with the experiment without shading obstacle. The model equipped with Planibel Bronze provided less than $50 \%$ of $S P D$ levels for wavelength range from $380-580 \mathrm{~nm}$ and probably $55 \%$ for the whole visible spectrum. It must be noted, that the external light conditions were in principle the same as in the first experiment. It 
is evident, that especially during autumn and winter, the monitored parameters of $C L_{A}$ and $C S$ would provide inappropriate values.

Figure 14. Results of SPD Levels Recorded in All Positions in All of the Models. The Ratios of SPD Levels Measured in Tested Models Compared to SPD Values in Reference Model for Two Spectral Ranges are Defined

\begin{tabular}{|c|c|c|c|c|c|c|c|c|}
\hline \multirow{3}{*}{ 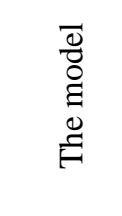 } & \multicolumn{8}{|c|}{ Absolute dose of visible spectrum $\left[\left(\mathrm{W} / \mathrm{m}^{2}\right) / \mathrm{nm}\right]$} \\
\hline & \multicolumn{4}{|c|}{ Wavelength interval $380-580 \mathrm{~nm}$} & \multicolumn{4}{|c|}{ Wavelength interval 380-780nm } \\
\hline & $\begin{array}{c}1 / 3 \\
\text { window }\end{array}$ & $\begin{array}{c}1 / 3 \\
\text { wall }\end{array}$ & $\begin{array}{c}2 / 3 \\
\text { window }\end{array}$ & $\begin{array}{c}2 / 3 \\
\text { wall }\end{array}$ & $\begin{array}{c}1 / 3 \\
\text { window }\end{array}$ & $\begin{array}{c}1 / 3 \\
\text { wall }\end{array}$ & $\begin{array}{c}2 / 3 \\
\text { window }\end{array}$ & $\begin{array}{c}2 / 3 \\
\text { wall }\end{array}$ \\
\hline Bronze & 1.87 & 0.89 & 0.94 & 0.43 & 3.91 & 1.97 & 2.11 & 1.00 \\
\hline Green & 3.63 & 1.77 & 1.38 & 0.61 & 6.20 & 3.06 & 2.48 & 1.12 \\
\hline Blue & 2.13 & 1.00 & 1.30 & 0.56 & 3.30 & 1.63 & 2.12 & 0.92 \\
\hline Reference & 4.15 & 1.91 & 1.86 & 0.86 & 7.82 & 3.70 & 3.66 & 1.78 \\
\hline \multicolumn{5}{|c|}{$\begin{array}{l}\text { The proportion of SPD in tested models } \\
\text { compared to reference model }\end{array}$} & \multicolumn{4}{|c|}{$\begin{array}{l}\text { The proportion of SPD in tested } \\
\text { models compared to reference model }\end{array}$} \\
\hline Bronze & 0.45 & 0.47 & 0.51 & 0.50 & 0.50 & 0.53 & 0.58 & 0.56 \\
\hline Green & 0.87 & 0.93 & 0.74 & 0.71 & 0.79 & 0.83 & 0.68 & 0.63 \\
\hline Blue & 0.51 & 0.52 & 0.70 & 0.65 & 0.42 & 0.44 & 0.58 & 0.52 \\
\hline Reference & 1.00 & 1.00 & 1.00 & 1.00 & 1.00 & 1.00 & 1.00 & 1.00 \\
\hline
\end{tabular}

Figure 15. Photopic Illuminance Levels Recorded in All Positions in All Models

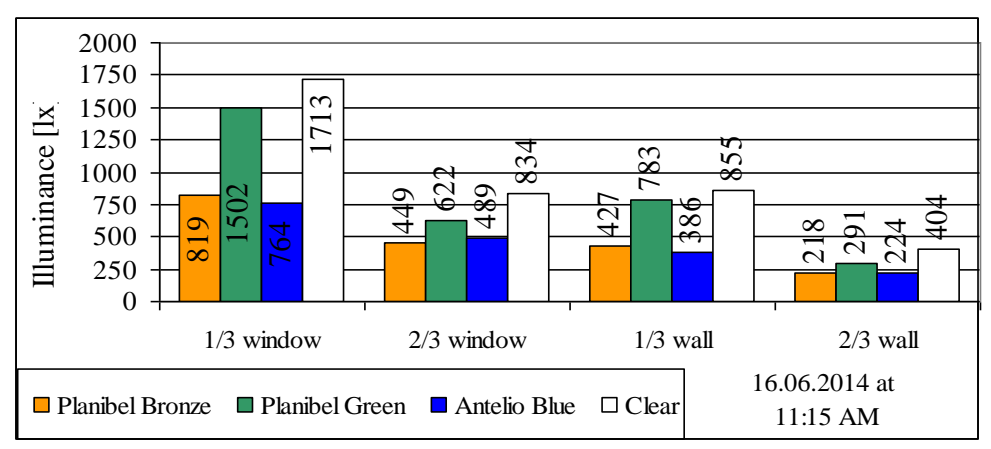

Figure 16. $C L_{A}$ Levels Estimated with Rea's Equation for All Positions in All of the Models

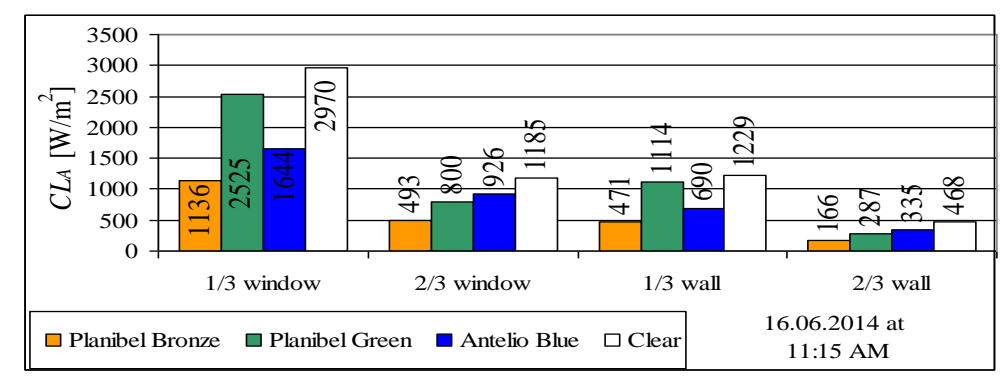

The initial hypothesis about shading obstacle influence was confirmed as can be seen in $C L_{A}$ and $C S$ levels in Fig 16-17. Planibel Bronze provided 
almost 1 third of $C L_{A}$ in comparison with clear glass. Also the $C S$ levels show more visible differences.

Figure 17. Computed CS Levels Acquired from Rea's Model in All Positions in All of the Models - with External Obstruction

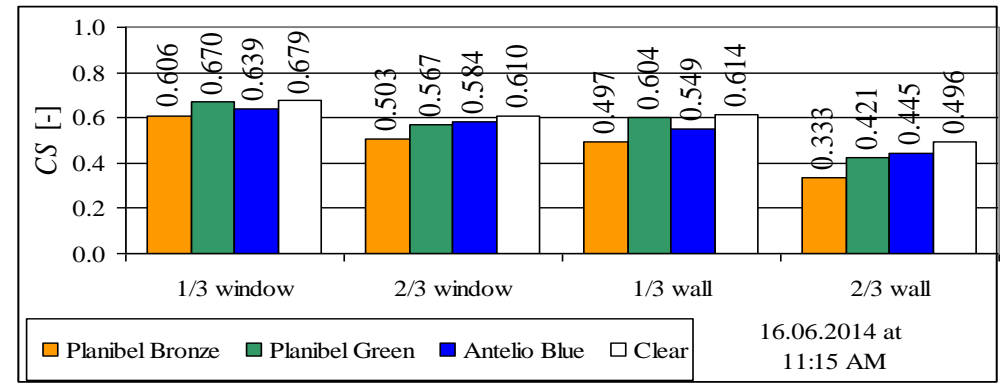

\section{Discussion}

The results from illuminance levels and $C L_{A}$ in the experiment without shading confirmed the fact that high illuminance levels are able to cover the deficiency in spectral composition. Despite the crucial blue doses filtration glazing - Planibel Bronze, the CS levels were appropriate for rhythms maintenance and there were minor differences with clear glass besides the last position in the $2 / 3$ of length from the window and orientation to the wall. The results of $C S$ were approximately 0.60 for clear glass and 0.49 for Planibel Bronze glazing. When an obstacle was applied, the $C S$ for particular positions became more significant (see Fig. 17). These outputs indicate that despite very high illuminance level with clear blue sky, the glazing, especially in combination with external dark coloured shading, caused noticeable negative impact on both visual and non-visual human response. When the illuminance level reached less than $400 \mathrm{~lx}$, the $C S$ levels were less than 0.5 . It can be expected, that especially during the winter season, in association with low external illuminance levels, the negative influence of inappropriate selection of glazing would be much more obvious.

\section{Conclusions}

The circadian photometry is still not investigated in detail. The establishment of precise requirements for non-visual indoor daylight evaluation is a long-lasting issue. Continual progress in the scientific field states the importance of this research. The establishment of this matter may in the future help design healthier buildings and so reduce the SAD and circadian disruptions occurrence, especially in industrialized countries in higher latitudes. 


\section{Acknowledgements}

This article was supported by Slovak Research and Development Agency under the contract No. APVV 0150-10 and project VEGA 1/0320/12.

\section{References}

[1] Vandewalle G, Balteau E, Phillips C, Dequeldre C, Moreau V, Sterpenich V, Albouy G, Darsaud A, Desseilles M, Dang-Vu TT, Peigneux P, Luxen A, Dijk DJ, Maquet P. 2006. Daytime light exposure dynamically enhances brain responses. Current Biology (2006), 16, 1616-1621.

[2] Stevens R. G, Blask D. E, Brainard G. C, Hansen J, Lockley S. W, Provencio I, Rea M. S, Reinlib L. 2007. Meeting Report: The Role of Environmental Lighting and Circadian Disruption in Cancer and Other Diseases. Environ Health Perspect (2007), 115, 1357-1362.

[3] Rollag M. D, Berson D. M, Provencio I. 2003. Melanopsin, Ganlion-cell photoreceptors and mammalian photoentrainment. Journal of biological rhythms (2003), 18/3, 227-234.

[4] Güler A. D, Ecker J. L, Lall G. S, Haq S, Altimus C. M, Liao H-W, Hattar S. 2008. Melanopsin cells are principal conduits for rod/cone input to nonimage forming vission. Nature (2008), 453/7191, 102-105.

[5] Andersen M, Gochenour S, Lockley S. W. 2013. Modeling „,non-visual“ effects of daylighting in a residential environment. Building and Environment 2013, http://infoscience.epfl.ch/record/188735/files/Ander sen2013_NonVisLightHousing_BAE-REV_clean2.pdf

[6] Panda S, Hogenesch J. B, Kay S. A. 2002. Circadian rhythms from flies to human. Nature 2002, 417, 329-335.

[7] Figueiro M. G, White R. D. 2013. Health consequences of shift work and implications for structural design. J. Perinatol 2013, 33/1, 17-23.

[8] MILLER D, BIERMAN A, FIGUEIRO M. G, SCHERNHAMMER E. S, REA, M. S. 2010. Ecological measurements of light exposure, activity and circadian disruption. Light Res. Technol. 2010, 42/3, 271-284.

[9] Pandi-Perumal S. R, Smits M, Spence, W, Srinivasan V, Cardinali D. P, Lowe A. D, Kayumov L. 2007. Dim light melatonin onset (DLMO): A tool for the analysis of circadian phase in human sleep and chronobiological disorders. Progress in Neutro-Psychopharmacology \& Biological Psychiatry 2007, 31, 1-11.

[10] Rea M. S, Figueiro M. G, Bullough J. D, Bierman A. 2005. A model of phototransduction by the human circadian system. Brain Research Reviews 2005, 50/2, 213-228.

[11]Brainard GC, Hanifin JP, Greeson JM, Byrne B, Glickman G, Gerner E, Rollag MD. 2001. Action spectrum for melatonin regulation in humans: evidence for a novel circadian photoreceptor. J Neurosci. 2001, 21, 64056412. 
[12] Thapan K, Arendt J, Skene DJ. 2001. An action spectrum for melatonin suppression: evidence for a novel non-rod, non-cone photoreceptor system in humans. J Physiol. 2001, 535, 261-267.

[13] Santhi N, Thorne HC, Johnsen S. 2012. The spectral composition of evening light and individual differences in the suppression of melatonin and delay of sleep in humans. Journal of Pineal Research, 2012, 53, 4759.

[14] Bellia L, Seraceni M. 2013. A proposal of a simplified model to evaluate circadian effects of light sources. Lighting Research and Technology published online 13 June 2013, DOI: 10.1177/1477153513490715, http://lrt.sagepub.com/ content/early/2013/05/22/1477153513490715.

[15] Rea MS, Figueiro MG, Bierman A, Hammer R. 2012. Modeling the spectral sensitivity of human circadian system. Lighting Research and Technology 2012, 44, 386-396, http://lrt.sagepub.com/content/44/4/386.

[16] Dartnall HJA, Bowmaker JK, Mollon JD. 1983. Human visual pigments: Microspectrophotometric results from the eyes of seven persons. Proc. $R$. Soc. Lond. B, 1983, 220, 115-130.

[17] Bellia L, Bisegna F. 2013. From radiometry to circadian photometry: A theoretical approach. Building and Environment. 2013, 62, 63-68.

[18] DIN V 5031-100 Strahlungsphysik im optischen Bereich und Lichttechnik - Teil 100: Über das Auge vermittelte, nichtvisuelle Wirkung des Lichts auf den Menschen - Größen, Formelzeichen und Wirkungsspektren. Juni 2009.

[19] Kolodyazhniy V, Späti J, Frey S, Götz T, Wirz-Justice A, Kräuchi K, Cajochen C, Wilhelm F. 2012. An Improved Method for Estimating Human Circadian Phase Derived From Multichannel Ambulatory Monitoring and Artificial Neural Networks, Chronobiology International 2012, 20, ISSN 0742-0528 print/1525-6073 online. 